\title{
Effective Ankaferd Hemostat Treatment For Severe Intractable Chronic Deep Leg Ulcer Associated With Behçet's Disease
}

\author{
Rafiye ÇİFTÇİLER ${ }^{10}$, Erdinç ÇİFTÇİLER ${ }^{2}$, İbrahim HAZNEDAROĞLU1D \\ ${ }^{1}$ Department of Hematology, Hacettepe University Faculty of Medicine, Ankara, Turkey \\ ${ }^{2}$ Department of General Surgery, Kızllcahamam State Hospital, Ankara, Turkey
}

\begin{abstract}
Ankaferd hemostat (Ankaferd Blood Stopper; ABS) is a pro-hemostatic agent affecting erythrocytes. In this article, we report a 50-year-old male patient who presented with a non-healing leg ulcer for one year. He had a past medical history of Behçet's disease (BD) diagnosed at the age of 29 and therapy was started. Patient's leg ulcer did not respond to any treatment. Topical ABS was applied to the patient's leg ulcer daily. Our experience suggested that local treatment of ABS can be a potentially successful therapy for the management of intractable or incurable chronic ulcers in patients with $\mathrm{BD}$ or for other ischemic or vasculitic skin problems.

Keywords: Ankaferd hemostat, Behçet's disease, leg ulcer.
\end{abstract}

Ankaferd hemostat [Ankaferd Blood Stopper (ABS), Istanbul, Turkey] is a hemostatic drug affecting red blood cell and fibrinogen interactions. ${ }^{1}$ ABS has been used as a hemostatic agent for the management of distinct types of clinical bleedings. $^{2}$ In addition to hemostatic functions, anti-inflammatory, ${ }^{3}$ anti-infective, ${ }^{4}$ anti-fungal, ${ }^{5}$ and anti-oxidative ${ }^{3}$ effects have been demonstrated for ABS. ABS has also been shown to accelerate wound healing. ${ }^{6,7}$ Behçet's disease (BD) is a thrombotic vasculitis characterized by oral and genital mucous membrane ulcers, uveitis, skin lesions and uncommonly leg ulcers. ${ }^{8}$ Leg ulcers are usually associated with vasculitis and/or deep vein thrombosis and refractory to conventional immunosuppressive therapies. ${ }^{9}$ In this article, we present a BD patient with leg ulcer who did not respond to conventional immunosuppressive therapy or other topical applications including surgery. Thus, we demonstrated the potential benefit of $\mathrm{ABS}$ in the treatment of a leg ulcer associated with BD.

\section{CASE REPORT}

A 50-year-old male patient presented with a non-healing leg ulcer for about one year. He had a past medical history of BD diagnosed at age 29 and therapy was started. During this period, his ulcers in oral and genital area continued to occur frequently. He was diagnosed as BD with recurrent oral, genital ulcers and positive pathergy test. ${ }^{10}$ The patient was treated with oral prednisolone (32 $\mathrm{mg} /$ day) and colchicine (2 mg/day) after the diagnosis. Oral and genital ulcers relatively improved. A leg ulcer occurred in his right leg after

Received: December 17, 2018 Accepted: March 04, 2019 Published online: April 26, 2019

Correspondence: Rafiye Çiftçiler, MD. Hacettepe Üniversitesi Tıp Fakültesi Hematoloji Bölümü, 06100 Sıhhiye, Ankara, Turkey. Tel: +90 505 - 5831798 e-mail: rafiyesarigul@gmail.com 


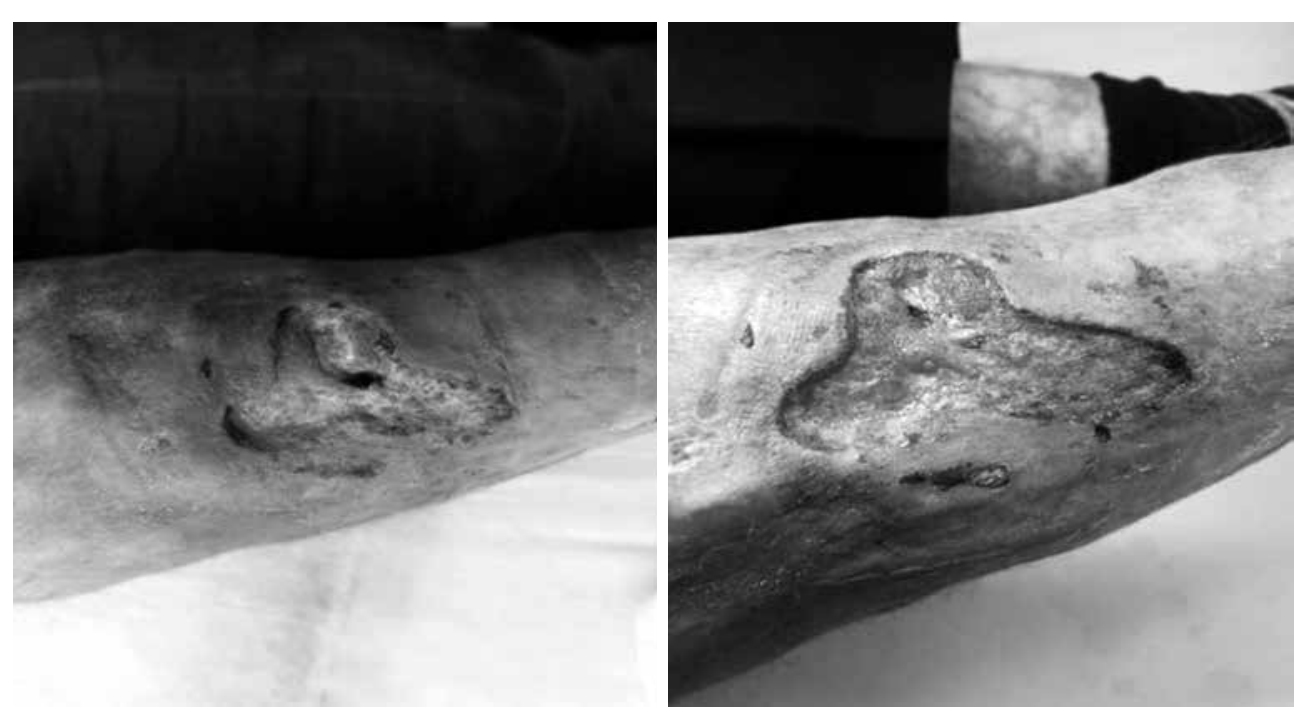

Figure 1. Patient's deep, infected and painful leg ulcer associated with Behçet's disease before treatment with Ankaferd hemostat.

wearing an anti-varicose bandage one year before. For about one year, the leg ulcer did not respond to conventional immunosuppressive therapy (such as prednisolone, azathioprine, cyclosporine, methotrexate, mycophenolate mofetil, rituximab) or tumor necrosis factor (TNF) inhibitors (infliximab). The patient underwent surgical treatment for the leg ulcer and hyperbaric oxygen therapy was applied for his wound.
The patient's leg ulcer did not respond to those treatments. When admitted to the general surgery outpatient clinic at age 50 , his right lower deep leg ulcers were located between the knee and ankle (Figure 1). His leg ulcer was painful, deep and irregular margined about $10 \times 10 \mathrm{~cm}$. Laboratory studies revealed a white blood cell count of $7.3 \times 10^{3} / \mu \mathrm{L}$, hemoglobin level of $10.1 \mathrm{~g} / \mathrm{dL}$ and platelet count was $317 \times 10^{3} / \mu \mathrm{L}$.
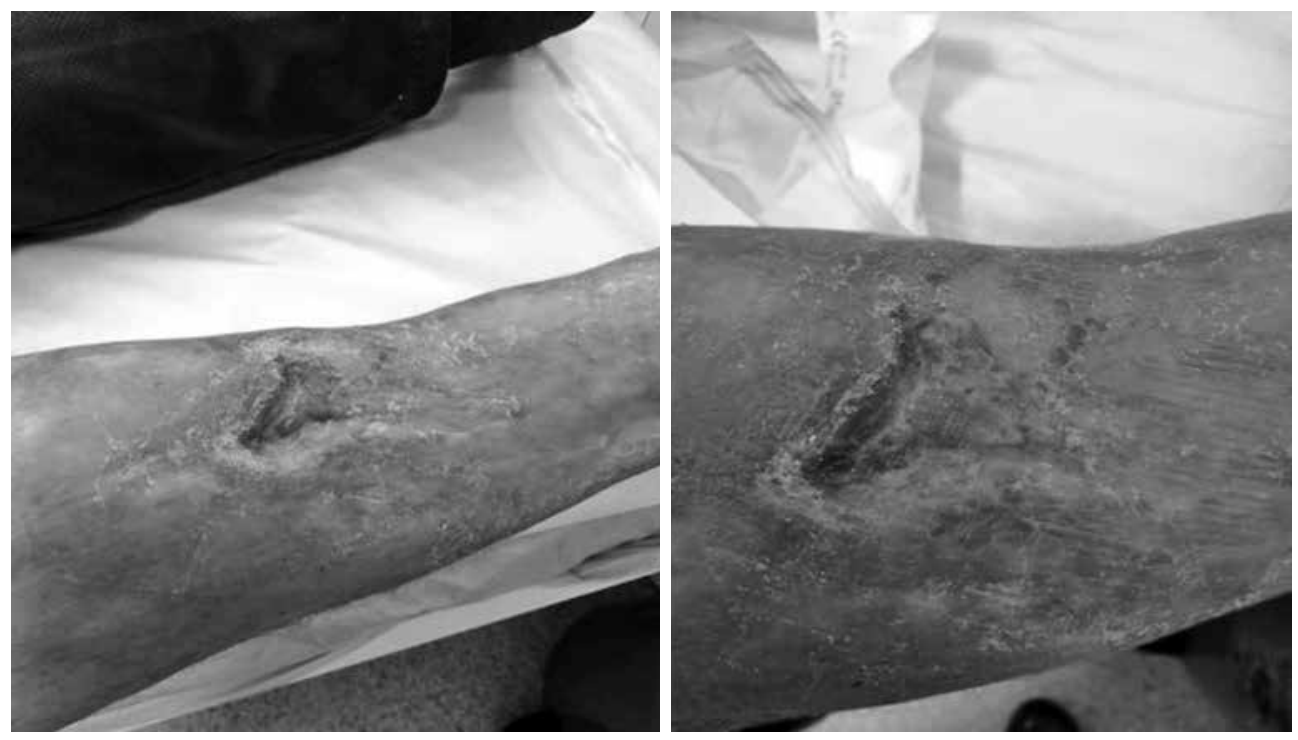

Figure 2. Patient's leg ulcer after treatment with Ankaferd hemostat. Erythema has almost disappeared, while granulation tissue has been replaced by normal skin. Depth and volume of wound also decreased. 
Serum C-reactive protein was $1.92 \mathrm{mg} / \mathrm{dL}$ and sedimentation was $11 \mathrm{~mm} /$ hour. A written informed consent was obtained from the patient.

Based upon the patient's clinical history, characterized by persistence and exacerbation of leg ulcers, and poor response to conventional treatment, we decided to administer topical ABS on his leg ulcer. The patient provided informed consent to receive the ABS local therapy. ABS was applied to the patient's ulcer daily. One month after initiating local ABS treatment, the right leg ulcer was markedly improved (Figure 2). After two months, the ulcer continued to improve. There was no adverse event due to the topical utilization of ABS.

\section{DISCUSSION}

Behçet's disease is a chronic disease characterized by relapsing vasculitis with oral and genital ulcers, cutaneous inflammation, uveitis, gastrointestinal and central nervous system manifestations. ${ }^{11}$ In general, 41 to $97 \%$ of $\mathrm{BD}$ patients have skin lesions such as aphthous ulcers, genital ulcers, erythema nodosum-like lesions, and papulopustular lesions, while leg ulcers are rare. ${ }^{9,12}$ The morbidity of $\mathrm{BD}$ is relatively high for chronic intractable ulcers. Appropriate treatment is chosen based on the organs involved and the clinical presentation of the patient. ${ }^{13}$ The molecular basis for the pathogenic mechanisms in chronic inflammation has been ascribed to the emergence of immunosuppressive biological therapeutics targeting TNF-alpha $(\alpha) .{ }^{14}$ The potential beneficial effect of ABS might be associated with reduced TNF- $\alpha$ in this case. Buyuktiryaki et al. ${ }^{15}$ demonstrated that ABS reduced oxidative stress by enhancement of antioxidant activity. ABS was associated with remarkably lower TNF- $\alpha$ and interleukin- 1 beta ( $\beta$ ) levels, significant improvement in histopathological findings and reduced apoptosis. Their findings indicated that ABS protects against intestinal damage due to its antioxidant and anti-inflammatory properties. ${ }^{15}$ In a clinical study, Patiroglu et al. ${ }^{16}$ disclosed the mucosal healing effects of ABS. ABS is effective in the prophylaxis and treatment of oral mucositis secondary to chemotherapy in childhood cancers. Moreover, Kaya et al. ${ }^{17}$ suggested that ABS could be effective for the management of experimental mucositis. Their study results showed that ABS decreased the inflammation, wound diameters, increased wound contraction and tissue fibrosis in burn induced rats. ${ }^{17}$ The results of another rat study demonstrated that $\mathrm{ABS}$ had a positive effect on second degree thermal burn healing. ${ }^{18}$ Aktas et al. ${ }^{19}$ explained the mechanism of due to ABS. In their study, ABS increased the number of cells anchoring the important markers of soft tissue healing such as collagen type 1 , collagen type 3, $\alpha$-smooth muscle actin, fibronectin, $\beta-2$ microglobulin, vascular endothelial growth factor, cyclooxygenase-2 and mononuclear phagocyte marker. They demonstrated that ABS enhanced the accumulation and biological actions of critical molecules representing the essential signals of early wound healing. Molecular responses associated with topical ABS application can be attributed to the ABS-induced acceleration in the healing rate at the early phase of the complicated wound healing process. Recently, we shared our own experience with ABS in a patient with burn skin wounds and showed the effectiveness of $\mathrm{ABS}$ for burn healing in a unique case presentation. ${ }^{20}$

In conclusion, ABS had potential wound healing effect for our patient's leg ulcer associated with BD. Our experience suggested that local treatment of ABS could be a potentially successful therapy for $\mathrm{BD}$ patients with intractable and drug resistant ulcers. Anti-inflammatory and antierythroid aggregation effects of $\mathrm{ABS}$ are thought to be effective in the wound healing process since effective hemostasis is the first part of the process.

\section{Declaration of conflicting interests}

The authors declared no conflicts of interest with respect to the authorship and/or publication of this article.

\section{Funding}

The authors received no financial support for the research and/or authorship of this article.

\section{REFERENCES}

1. Beyazit Y, Kurt M, Kekilli M, Goker H, Haznedaroglu IC. Evaluation of hemostatic effects of Ankaferd as an alternative medicine. Altern Med Rev 2010;15:329-36. 
2. Goker H, Haznedaroglu IC, Ercetin S, Kirazli S, Akman U, Ozturk Y, et al. Haemostatic actions of the folkloric medicinal plant extract Ankaferd Blood Stopper. J Int Med Res 2008;36:163-70.

3. Koçak E, Akbal E, Taş A, Köklü S, Karaca G, Can M, et al. Anti-inflammatory efficiency of Ankaferd blood stopper in experimental distal colitis model. Saudi J Gastroenterol 2013;19:126-30.

4. Saribas Z, Sener B, Haznedaroglu IC, Hascelik G, Kirazli S, Goker H. Antimicrobial activity of ankaferd blood stopper ${ }^{\circledR}$ against nosocomial bacterial pathogens. Cent. Eur J Med 2010;5:198-202.

5. Ciftci S, Keskin F, Keceli Ozcan S, Erdem MA, Cankaya B, Bingol R, et al. In Vitro Antifungal Activity of Ankaferd Blood Stopper Against Candida albicans. Curr Ther Res Clin Exp 2011;72:120-6.

6. Kuru S, Kismet K, Bag YM, Barlas AM, Senes M, Durak M, et al. Does the application of Ankaferd Blood Stopper rectally have positive effects on the healing of colorectal anastomosis and prevention of anastomotic leakage? An experimental study. Biomed Pharmacother 2017;96:968-73.

7. Hasgul R, Uysal S, Haltas H, Akyol S, Yuksel Y, Gurel A, et al. Protective effects of Ankaferd blood stopper on aspirin-induced oxidative mucosal damage in a rat model of gastric injury. Toxicol Ind Health 2014;30:888-95.

8. Michelson JB, Chisari FV. Behçet's disease. Surv Ophthalmol 1982;26:190-203.

9. Jung JY, Kim DY, Bang D. Leg ulcers in Behçet's disease. Br J Dermatol 2008;158:178-9.

10. International Team for the Revision of the International Criteria for Behçet's Disease (ITR-ICBD). The International Criteria for Behçet's Disease (ICBD): a collaborative study of 27 countries on the sensitivity and specificity of the new criteria. J Eur Acad Dermatol Venereol 2014;28:338-47.

11. Sakane T, Takeno M, Suzuki N, Inaba G. Behçet's disease. N Engl J Med 1999;341:1284-91.

12. Lee ES, Bang D, Lee S. Dermatologic manifestation of Behçet's disease. In: Lee S, Bang D, Lee ES, Sohn $\mathrm{S}$, editors. Behçet's Disease A Guide to its Clinical Understanding. Berlin Heidelberg: Springer; 2001. p. 129-36.

13. Hatemi G, Silman A, Bang D, Bodaghi B, Chamberlain AM, Gul A, et al. Management of Behçet disease: a systematic literature review for the European League Against Rheumatism evidencebased recommendations for the management of Behçet disease. Ann Rheum Dis 2009;68:1528-34.

14. Li Y, Wang Z, Zhao Y, Luo Y, Xu W, Marion TN, et al. Successful mesenchymal stem cell treatment of leg ulcers complicated by Behcet disease: A case report and literature review. Medicine (Baltimore) 2018;97:e0515.

15. Buyuktiryaki M, Tayman C, Koyuncu I, Cakir U, Taskin Turkmenoglu T, Cakir E, et al. Therapeutic and preventative effects of ankaferd blood stopper in an experimental necrotizing enterocolitis model. Biomed Pharmacother 2019;110:105-10.

16. Patıroğlu T, Erdoğ Şahin N, Ünal E, Kendirci M, Karakükcü M, Özdemir MA. Effectiveness of ankaferd bloodstopper in prophylaxis and treatment of oral mucositis in childhood cancers evaluated with plasma citrulline levels. Turk J Haematol 2018;35:85-6.

17. Kaya H, Gokdemir MT, Sogut O, Demir T, Koçarslan S. Effects of folk medicinal plant extract ankaferd blood stopper on burn wound healing. Acta Medica Mediterranea. 2013;29:497-502.

18. Ozcan EC, Senol S, Tokgoz Y, Kuloglu T. The regenerative effects of hemostatic plant extract in second degree burn wound. Ulutas Med J 2017;3:78-84.

19. Aktaş A, Er N, Korkusuz P, Zeybek D, Onur MA, Tan G, et al. Ankaferd-induced early soft tissue wound healing in an experimental rat model. Turkiye Klinikleri J Med Sci 2013;33:1344-53.

20. Çiftçiler R, Haznedaroğlu İC. On being a "physician patient" with his own experimental therapeutic drug. Turk J Haematol 2018;35:302-3. 